\title{
Introduction to the Handbooks of Japanese Language and Linguistics
}

Comprising twelve substantial volumes, the Handbooks of Japanese Language and Linguistics (HJLL) series provides a comprehensive survey of practically all the major research areas of Japanese linguistics on an unprecedented scale, together with surveys of the endangered languages spoken in Japan, Ryukyuan and Ainu. What follows are introductions to the individual handbooks, to the general conventions adopted in this series, and an overview of the minimum essentials of contemporary Standard Japanese. Fuller descriptions of the languages of Japan, Japanese grammar, and the history of the Japanese language are available in such general references as Martin (1975), Shibatani (1990), and Frellesvig (2010).

\section{Geography, Population, and Languages of Japan}

Japan is situated in the most populous region of the world - Asia, where roughly one half of the world population of seven billion speak a variety of languages, many of which rank in the top tier among languages of the world in terms of number of native speakers. Japanese is spoken by more than 128 million people (as of 2013), who live mostly in Japan but also in Japanese emigrant communities around the world, most notably Hawaii, Brazil, and Peru. In terms of the number of native speakers, Japanese ranks ninth among the world's languages. Due partly to its rich and long literary history, Japanese is one of the most intensely studied languages in the world and has received scrutiny both within the domestic grammatical tradition and in traditions outside Japan such as the Chinese philological tradition, European structural linguistics, and the tradition of generative grammar originating in America. The Handbooks of Japanese Language and Linguistics intend to capture the achievements garnered over the years through analyses of a wide variety of phenomena in a variety of theoretical frameworks.

As seen in Map 1, where Japan is shown graphically superimposed on Continental Europe, the Japanese archipelago has a vast latitudinal extension of approximately 3,000 kilometers ranging from the northernmost island, roughly corresponding in latitude to Stockholm, Sweden, to the southernmost island, roughly corresponding in latitude to Sevilla, Spain.

Contrary to popular assumption, Japanese is not the only language native to Japan. The northernmost and southernmost areas of the Japanese archipelago are inhabited by people whose native languages are arguably distinct from Japanese. The southernmost sea area of Okinawa Prefecture is dotted with numerous small islands 


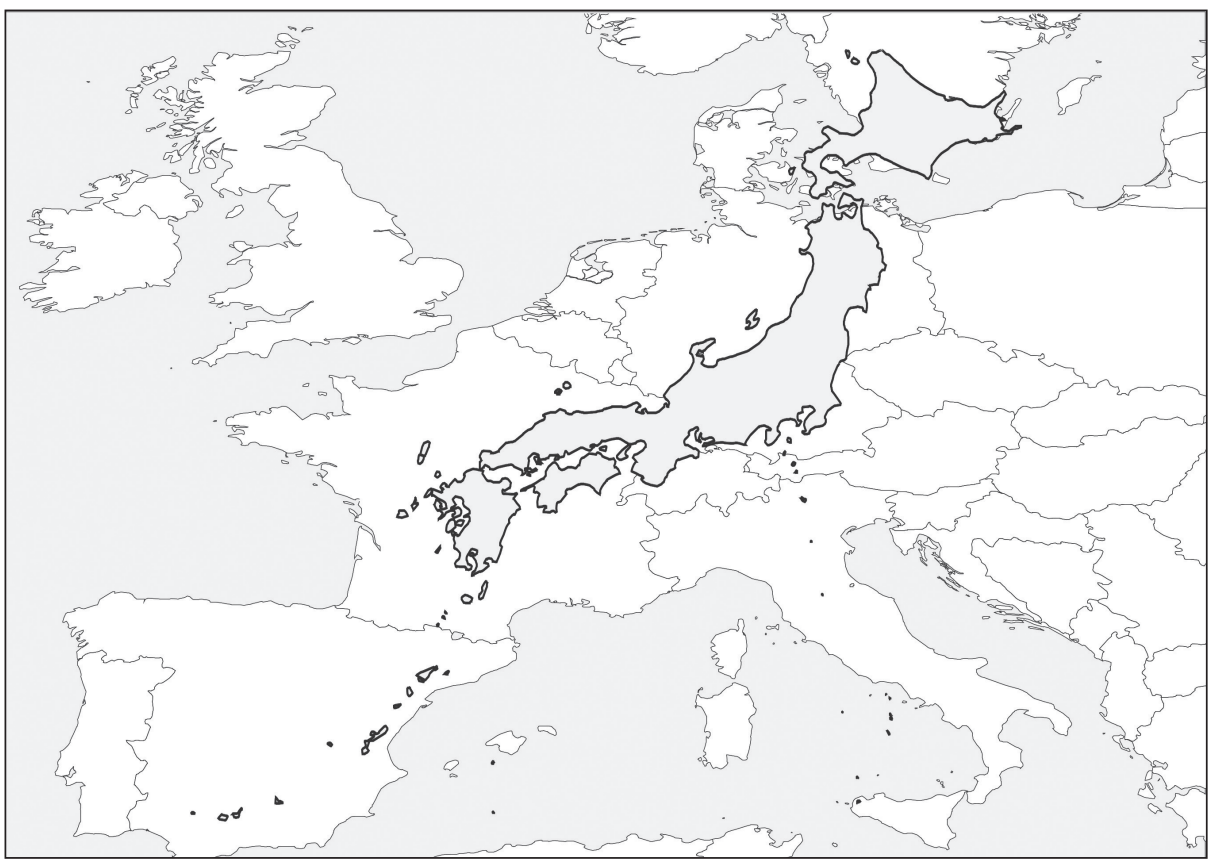

Map 1: Japan as overlaid on Europe

Source: Shinji Sanada. 2007. Hōgen wa kimochi o tsutaeru [Dialects convey your heart].

Tokyo: Iwanami. p. 68

where Ryukyuan languages are spoken. Until recent years, Japanese scholars tended to treat Ryukyuan language groups as dialects of Japanese based on fairly transparent correspondences in sounds and grammatical categories between those language groups and mainland Japanese, although the two are mutually unintelligible. Another reason that Ryukyuan languages have been treated as Japanese dialects is that the Ryukyuan islands and Japan form a single nation. In terms of nationhood, however, Ryukyu was an independent kingdom until the beginning of the seventeenth century, when it was forcibly annexed to the feudal domain of Satsuma in southern Kyushu.

A more recent trend is to treat Ryukyuan as forming a branch of its own with the status of a sister language to Japanese, following earlier proposals by Chamberlain (1895) and Miller (1971). Many scholars specializing in Ryukyuan today even confer language status to different language groups within Ryukyuan, such as the Amami language, Okinawan language, Miyako language, etc., which are grammatically distinct to the extent of making them mutually unintelligible. The prevailing view now has Japanese and Ryukyuan forming the Japonic family as daughter languages of Proto-Japonic. HJLL follows this recent trend of recognizing Ryukyuan as a sister language to Japanese and devotes one full volume to it. The Handbook of the Ryukyuan Languages provides the most up-to-date information pertaining to Ryukyuan lan- 
guage structures and use, and the ways in which these languages relate to Ryukyuan society and history. Like all the other handbooks in the series, each chapter delineates the boundaries and research history of the field it addresses, presents the most important and representative information on the state of research in that field, and spells out future research desiderata. This volume also includes a comprehensive bibliography of Ryukyuan linguistics.

The situation with Ainu, another language indigenous to Japan, is much less clear in terms of its genealogical relationship to Japanese. Various suggestions have been made relating Ainu to Paleo-Asiatic, Ural-Altaic, and Malayo-Polynesian or to such individual languages as Gilyak and Eskimo, besides the obvious candidate of Japanese as a sister language. The general consensus, however, points to the view that Ainu is related to Japanese only indirectly, if at all, via the Altaic family with its Japanese-Korean sub-branch (see Miller 1971; Shibatani 1990: 5-7 for an overview). Because Ainu has had northern Japan as its homeland and because HJLL is also concerned with various aspects of Japanese linguistics scholarship in general, we have decided to include a volume devoted to Ainu in this series. The Handbook of the Ainu Language outlines the history and current state of the Ainu language, offers a comprehensive survey of Ainu linguistics, describes major Ainu dialects in Hokkaido and Sakhalin, and devotes a full section to studies dealing with typological characteristics of the Ainu language such as polysynthesis and incorporation, person marking, plural verb forms, and aspect and evidentials.

\section{History}

Japan's rich and long literary history dates back to the early seventh century, when the Japanese learned to use Chinese characters in writing Japanese. Because of the availability of abundant philological materials, the history of the Japanese language has been one of the most intensely pursued fields in Japanese linguistics. While several different divisions of Japanese language history have been proposed, Frellesvig (2010) proposes the following four linguistic periods, each embracing the main political epochs in Japanese history.

1. Old Japanese 700-800 (Nara period, 712-794)

2. Early Middle Japanese $800-1200$ (Heian period, 794-1185)

3. Late Middle Japanese 1200-1600 (Kamakura period, 1185-1333;

Muromachi period, 1333-1573)

4. Modern Japanese $\quad$ 1600- $\quad$ (Edo, 1603-1868; Meiji, 1868-1912;

Taishô, 1912-1926; Shôwa, 1926-1989;

Heisei, 1989-2019; Reiwa 2019-) 
This division reflects a major boundary between Pre-modern and Modern Japanese brought about by some radical changes in linguistic structure during the Late Middle Japanese period. Modern Japanese is often further subdivided into Early Modern (Edo, 1603-1868), Modern (Meiji, 1868-1912; Taishô, 1912-1926), and Present-day Japanese (Shôwa, 1926-1989; Heisei, 1989-2019; Reiwa 2019-).

The Handbook of Japanese Historical Linguistics will present the latest research on better studied topics, such as segmental phonology, accent, morphology, and certain salient syntactic phenomena such as focus constructions. It will also introduce areas of study that have traditionally been underrepresented, ranging from syntax and Sino-Japanese (kanbun) materials to historical pragmatics, and demonstrate how these contribute to a fuller understanding of the overall history of Japanese, as well as outlining larger-scale tendencies and directions of change that have taken place within the language over its attested history. Major issues in the reconstruction of prehistoric Japanese and in the individual historical periods from Old Japanese to Modern Japanese are discussed, including writing and the materials available for historical study, influences of Sino-Japanese on Japanese, the histories of different vocabulary strata, the history of honorifics and polite language, generative diachronic syntax, and the development of case marking.

\section{Geographic and social variations}

Because of the wide geographical spread of the Japanese archipelago from north to south, characterized by high mountain ranges, deep valleys, and wide rivers as well as numerous islands, Japanese has developed a multitude of dialects, many of which differ from each other in a way more or less like current descendants of the Romance language family. Like historical studies, the research tradition of dialect studies has a unique place in Japanese linguistics and has attracted a large number of students and amateur collectors of dialect forms as well as professional linguists. The Handbook of Japanese Dialects surveys the historical backdrop to theoretical frameworks of contemporary studies in Japanese geolinguistics and includes analyses of prominent research topics in cross-dialectal perspective, such as accentual systems, honorifics, verbs of giving, and nominalizations. The volume also devotes major attention to sketching the grammars of dialects from the northern island of Hokkaido to the southern island of Kyushu, allowing a panoramic view of differences and similarities among representative dialects throughout Japan.

Besides having a physical setting that has fostered geographic variation, the society of Japan has exhibited differing types of social structure over the years, starting from the time of the nobility and court life of the Old and Early Middle Japanese periods, through the caste structure of the feudalistic Late Middle and Early Modern Japanese periods, to the modern democratic society of the Modern and Present-day 
Japanese periods. These different social structures have spawned a variety of social dialects, including power- and gender-based varieties of Japanese. The Handbook of Japanese Sociolinguistics examines a wide array of sociolinguistic topics ranging from the history of Japanese sociolinguistics, including foreign influences and internal innovations, to the central topics of variation due to social stratification, gender differences, and discourse genre. Specific topics include honorifics and women's speech, critical discourse analysis, the pragmatics of political discourse, contact-induced change, emerging new dialects, Japanese language varieties outside Japan, and language policy.

\section{Lexicon and phonology}

The literary history of Japan began with early contacts with China. Chinese apparently began to enrich the Japanese lexicon even in pre-historic periods, when such deeply assimilated words as uma 'horse' and ume 'plum' are believed to have entered the language. Starting in the middle of the sixth century, when Buddhism reached Japan, Chinese, at different periods and from different dialect regions, has continuously contributed to Japanese in an immeasurable way affecting all aspects of grammar, but most notably the lexicon and the phonological structure, which have sustained further and continuous influences from European languages from the late Edo period on. Through these foreign contacts, Japanese has developed a complex vocabulary system that is composed of four lexical strata, each with unique lexical, phonological, and grammatical properties: native Japanese, mimetic, Sino-Japanese, and foreign (especially English).

The Handbook of Japanese Lexicon and Word Formation presents a comprehensive survey of the Japanese lexicon, word formation processes, and other lexical characteristics seen in the four lexical strata of contemporary Japanese. The agglutinative character of the language, coupled with its intricate system of vocabulary strata, makes it possible for compounding, derivation, conversion, and inflection to be closely intertwined with syntactic structure, giving rise to theoretically intriguing interactions between word formation processes and syntax that are not easily found in inflectional, isolate, or polysynthetic types of languages. Theoretically oriented studies associated with these topics are complemented by ones oriented toward lexical semantics, which also bring to light theoretically challenging issues involving the morphology-syntax interface.

The four lexical strata characterizing the Japanese lexicon are also relevant to Japanese phonology, as each stratum has some characteristic sounds and sound combinations not seen in the other strata. The Handbook of Japanese Phonetics and Phonology describes and analyzes the basic phonetic and phonological structures of modern Japanese with a main focus on standard Tokyo Japanese, relegating the 
topics of dialect phonetics and phonology to the Handbook of Japanese Dialects. It includes several chapters dealing with phonological processes unique to the Sino-Japanese and foreign strata as well as to the mimetic stratum. Other topics include word tone/accent, mora-timing, sequential voicing (rendaku), consonant geminates, vowel devoicing and diphthongs, and the appearance of new consonant phonemes. Also discussed are phonetic and phonological processes within and beyond the word such as rhythm, intonation, and the syntax-phonology interface, as well as issues bearing on other subfields of linguistics such as historical and corpus linguistics and research on the L2 acquisition of Japanese phonology.

\section{Syntax and semantics}

Chinese loans have also affected Japanese syntax, though it is unclear to what extent they have affected Japanese semantics beyond the level of lexical semantics. In particular, Chinese loans form two distinct lexical categories in Japanese - verbal nouns, forming a subcategory of the noun class, and adjectival nouns (keiyō dōshi), which are recognized by some as forming major independent lexical categories along with noun, verb, and adjective classes. The former denote verbal actions and, unlike regular nouns denoting objects and thing-like entities, can function as verbs by combining with the light verb suru, which is obviously related to the verb suru 'do'. The nominal-verbal Janus character of verbal nouns results in two widely observed syntactic patterns that are virtually synonymous in meaning; e.g., benkyoo-suru (studying-DO) 'to study' and benkyoo o suru (studying ACC do) 'do studying'. As described in the Handbook of Japanese Lexicon and Word Formation, the lexical category of adjectival noun has been a perennial problem in the analysis of Japanese parts of speech. Property-concept words that fall into this class, such as kirei 'pretty' and kenkoo 'health/healthy', do not inflect by themselves, unlike native Japanese adjectives, and, like nouns, require the inflecting copula $d a$ to perform the predication function, hence the label of adjectival noun for this class. However, many of these cannot head noun phrases - the hallmark of the nominal class - and some even yield nouns via -sa nominalization, which is not possible with regular nouns.

The Handbook of Japanese Lexicon and Word Formation and the Handbook of Japanese Syntax make up twin volumes because many chapters in the former deal with syntactic phenomena, as the brief discussion above on the two Sino-Japanese lexical categories clearly indicates. The syntax handbook covers a vast landscape of Japanese syntax from three theoretical perspectives: (1) traditional Japanese grammar, known as kokugogaku (lit. national-language study), (2) the functional approach, and (3) the generative grammar framework. Broad issues analyzed include sentence types and their interactions with grammatical verbal categories, grammatical relations (topic, subject, etc.), transitivity, nominalizations, grammaticalization, 
voice (passives and causatives), word order (subject, scrambling, numeral quantifiers, configurationality), case marking ( $\mathrm{ga} /$ no conversion, morphology and syntax), modification (adjectives, relative clause), and structure and interpretation (modality, negation, prosody, ellipsis). These topics have been pursued vigorously over many years under different theoretical persuasions and have played important roles in the development of general linguistic theory. For example, the long and sustained study of the grammatical relations of subject and topic in Japanese has had a significant impact on the study of grammatical relations in European as well as Austronesian languages. In the study of word order, the analysis of Japanese numeral quantifiers has been used as one of the leading pieces of evidence for the existence of a movement rule in human language. With regard to case marking, the way subjects are case marked in Japanese has played a central role in the study of case marking in the Altaic language family. Recent studies of nominalizations have been central to the analysis of their modification and referential functions in a wide variety of languages from around the globe, with far-reaching implications for past studies of such phenomena as parts of speech, (numeral) classifiers, and relative clauses. And the study of how Japanese prosody plays a crucial role in interpretation has become the basis for some important recent developments in the study of wh-questions.

The Handbook of Japanese Semantics and Pragmatics presents a collection of studies on linguistic meaning in Japanese, either as conventionally encoded in linguistic form (the field of semantics) or as generated by the interaction of form with context (the field of pragmatics). The studies are organized around a model that has long currency in traditional Japanese grammar, whereby the linguistic clause consists of a multiply nested structure centered in a propositional core of objective meaning around which forms are deployed that express progressively more subjective meaning as one moves away from the core toward the periphery of the clause. Following this model, the topics treated in this volume range from aspects of meaning associated with the propositional core, including elements of meaning structured in lexical units (lexical semantics), all the way to aspects of meaning that are highly subjective, being most grounded in the context of the speaker. In between these two poles of the semantics-pragmatics continuum are elements of meaning that are defined at the level of propositions as a whole or between different propositions (propositional logic) and forms that situate propositions in time as events and those situating events in various modes of reality including non-actual worlds, e.g., those hoped for (desiderative meaning), denied (negation), hypothesized (conditional meaning), or viewed as ethically or epistemologically possible or necessary (epistemic and deontic modality). Located yet closer to the periphery of the Japanese clause are a rich array of devices for marking propositions according to the degree to which the speaker is committed to their veracity and for marking differing perceptual and cognitive modalities as well as for distinguishing information that is presupposed versus affirmed.

These studies in Japanese syntax and semantics are augmented by cross-linguistic studies that examine various topics in these fields from the perspectives of lan- 
guage universals and the comparative study of Japanese and other languages. The Handbook of Japanese Contrastive Linguistics sets as its primary goal uncovering principled similarities and differences between Japanese and other languages around the globe and thereby shedding new light on the universal and language-particular properties of Japanese. Topics ranging from inalienable possession to numeral classifiers, from spatial deixis to motion typology, from nominalization to subordination, and other topics closely related to these are taken up within the framework of typological universals. Additionally, various aspects of Japanese such as resultative-progressive polysemy, entailment of event realization, internal-state predicates, topic constructions, and interrogative pronouns, are compared and contrasted with other specific languages, including Ainu, Koryak, Chinese, Korean, Newar, Thai, Burmese, Tagalog, Kapampangan, Lamaholot, Romanian, French, Spanish, German, English, Swahili, Sidaama, and Mayan languages.

\section{Psycholinguistics and Applied Linguistics}

HJLL includes two volumes containing topics related to a wider application of Japanese linguistics and to those endeavors seeking grammar-external evidence for the psycho-neurological reality of the structure and organization of grammar. Incorporating recent research on the study of the cognitive processes and brain mechanisms underlying language use, language acquisition, and language disorders, the Handbook of Japanese Psycholinguistics presents the current state of scholarly understanding of the mechanisms of language acquisition and language processing. In particular, the volume seeks answers to the question of how Japanese is learned/ acquired as a first or second language, and pursues the question of how Japanese sentences are comprehended and produced. The chapters in the acquisition section allow readers to acquaint themselves with issues pertaining to the question of how grammatical features (including pragmatic and discourse features) are acquired and how the language domain of the brain develops, with respect to both language particular and universal features. Specific topics dealt with include Japanese children's perceptual development, the conceptual and grammatical development of nouns, Japanese Specific Language Impairment, narrative development in the L1 cognitive system, and L2 Japanese acquisition and its relation to L1 acquisition. The language processing section focuses on both L1 and L2 Japanese processing, covering topics such as the role of prosodic information in production/comprehension, the processing of complex grammatical structures such as relative clauses, processing issues related to variable word order, and lexical and sentence processing in L2 by speakers of different native languages.

The Handbook of Japanese Applied Linguistics complements the Psycholinguistics volume by examining language acquisition from broader sociocultural perspec- 
tives, including language as a means of communication and as a social behavioral system, emphasizing pragmatic development as central to both L1 and L2 acquisition and to overall human development. Topics approached from these perspectives include the role of caregiver speech in early language development, literacy acquisition, and the acquisition of writing skills. Closely related to L1 and L2 acquisition and development are studies of bilingualism/multilingualism and the teaching and learning of foreign languages, including Japanese as a second language, where topics are discussed such as cross-lingual transfer from L1 to L2, learning errors, and proficiency assessment of second language acquisition. Chapters dealing with topics more squarely falling in the domain of applied linguistics cover issues in corpus/computational linguistics (including discussions of CHILDES for Japanese and the YK corpus, both widely used in research on Japanese as a second language), clinical linguistics (including discussions of language development in children with hearing impairment and other language disorders, Down syndrome, and autism), and translation and interpretation. Technically speaking, Japanese Sign Language is not a variety of Japanese, but in view of the importance of this language in Japanese society and because of the rapid progress in sign language research in Japan and abroad and for what it has to offer to the general theory of language, chapters dealing with Japanese Sign Language are also included in this volume.

\section{Grammatical sketch of Standard Japanese}

The following pages offer a brief overview of Japanese grammar as an aid to a quick grasp of the structure of Japanese that may prove useful in studying individual, thematically organized handbooks in this series. One of the difficult problems in describing non-European languages using familiar technical terms derived from the European grammatical tradition concerns mismatches between what the glosses may imply and what grammatical categories they are used to denote in the description. We will try to illustrate this problem below by way of a warning not to take all glosses at their face value. But first some remarks are in order about the conventions of transcription of Japanese, glossing of examples, and their translations used in this series.

\subsection{Writing, Alphabetic Transcription, and Pronunciation}

Customarily, Japanese is written by using a mixture of Chinese characters (for content words), hiragana (for function words such as particles, suffixes, and inflectional endings), katakana (for foreign loans and mimetics), and sometimes the Roman alphabet. Because Japanese had no indigenous writing system, it developed two phonogram systems for representing the phonological unit of "mora," namely hiragana 
and katakana, by simplifying or abbreviating (parts of) Chinese characters. Hiragana and katakana syllabaries are shown in Table 1, together with the alphabetic transcriptions adopted in the HJLL series.

Table 1: Alphabetic transcriptions adopted in HJLL

\begin{tabular}{|c|c|c|c|c|c|c|c|c|c|c|c|}
\hline transcription & $a$ & ka & sa & ta & na & ha & $m a$ & $y a$ & ra & $w a$ & $n$ \\
\hline hiragana & あ & か & さ & た & な & は & ま & や & 5 & わ & h \\
\hline katakana & ア & 力 & サ & タ & ナ & 八 & P & ヤ & ラ & $ワ$ & ン \\
\hline transcription & $i$ & ki & si & $t i$ & ni & hi & mi & - & ri & - & \\
\hline hiragana & い & き & し & ち & に & ひ & み & - & $\eta$ & - & \\
\hline katakana & イ & キ & シ & チ & 二 & ヒ & ミ & - & リ & - & \\
\hline transcription & $u$ & ku & $s u$ & $t u$ & nu & hu & $m u$ & yu & ru & - & \\
\hline hiragana & う & $<$ & す & כ & $ぬ$ & 小 & む & ゆ & る & - & \\
\hline katakana & ウ & ク & ス & ツ & 又 & フ & 厶 & ᄀ ᄀ & ル & - & \\
\hline transcription & $e$ & ke & se & te & ne & he & me & - & re & - & \\
\hline hiragana & え & け & せ & $\tau$ & ね & $\uparrow$ & め & - & れ & - & \\
\hline katakana & I & ケ & セ & テ & ネ & $\uparrow$ & x & - & レ & - & \\
\hline transcription & 0 & ko & so & to & no & ho & mo & yo & ro & 0 & \\
\hline hiragana & お & こ & そ & と & の & ほ & も & よ & ろ & を & \\
\hline katakana & オ & コ & ソ & 卜 & ノ & ホ & モ & $\exists$ & 口 & 7 & \\
\hline
\end{tabular}

Because of phonological change, the columns indicated by strikethroughs have no letters in contemporary Japanese, although they were filled in with special letters in classical Japanese. If all the strikethroughs were filled, the chart would contain 50 letters for each hiragana and katakana, so the syllabary chart is traditionally called Gojū-on zu (chart of 50 sounds). To these should be added the letter $h$ or $ン$ representing a moraic nasal $[\mathrm{N}]$, on the rightmost column.

The "50-sound chart," however, does not exhaust the hiragana and katakana letters actually employed in Japanese, because the basic consonant sounds $(k, s, t, h)$ have variants. The sound represented by the letter $h$ is historically related to the sound represented by $p$, and these voiceless obstruents $(k, s, t$, and $p)$ have their respective voiced counterparts $(g, z, d$, and $b$ ). Table 2 shows letters for these consonants followed by five vowels. 
Table 2: Letters for voiced obstruents and bilabial [p]

\begin{tabular}{|l|c|c|c|c|c|}
\hline transcription & $g a$ & $z a$ & $d a$ & $b a$ & $p a$ \\
\hline hiragana & が & ざ & だ & ば & ぱ \\
\hline katakana & ガ & ザ & ダ & バ & パ \\
\hline transcription & $g i$ & $z i$ & $z i$ & $b i$ & $p i$ \\
\hline hiragana & ぎ & じ & ぢ & び & ぴ \\
\hline katakana & ギ & $シ ゙$ & ヂ & ビ & ピ \\
\hline transcription & $g u$ & $z u$ & $d u$ & $b u$ & $p u$ \\
\hline hiragana & ぐ & ず & ブ & ぶ & ぷ \\
\hline katakana & グ & ズ & ヅ & ブ & プ \\
\hline transcription & $g e$ & $z e$ & $d e$ & $b e$ & $p e$ \\
\hline hiragana & げ & ぜ & で & ベ & ペ \\
\hline katakana & ゲ & ゼ & デ & ベ & ペ \\
\hline transcription & $g o$ & $z o$ & $d o$ & bo & $p o$ \\
\hline hiragana & ご & ぞ & ど & ぼ & ぽ \\
\hline katakana & ゴ & ゾ & ド & ボ & ポ \\
\hline
\end{tabular}

It is important to note that Tables 1 and 2 show the conventional letters and alphabetical transcription adopted in the text of the HJLL series; they are not intended to represent the actual pronunciations of Japanese vowels and consonants. For example, among the vowels, the sound represented as " $u$ " is pronounced as [u] with unrounded lips. Consonants may change articulation according to the vowels that follow. The following will require particular attention.

There are two Romanization systems widely used in Japan. One, known as the Hepburn system, is more widely used in public places throughout Japan such as train stations, street signs, as well as in some textbooks for learners of Japanese. This system is ostensibly easier for foreigners familiar with the English spelling system. Another, the Kunreishiki (the cabinet ordinance system), is phonemic in nature and is used by many professional linguists. The essential differences between the two Romanization systems center on palatalized and affricate consonants, as shown in Table 3 below with some representative syllables for which the two Romanization renditions differ: 
Table 3: Two systems of Romanization

\begin{tabular}{|c|c|c|c|}
\hline Hiragana & IPA & Hepburn & Kunreishiki \\
\hline L & [Si] & shi & si \\
\hline$し ゃ$ & [ja] & sha & sya \\
\hline しゅ & {$[\mathrm{Ju}]$} & shu & syu \\
\hline しょ & [ $[0]$ & sho & syo \\
\hline じ and ぢ & [dzi] & $\mathrm{ji}$ & zi \\
\hline じゃ & [dza] & ja & zya \\
\hline じゅ & [dzul] & ju & zyu \\
\hline じょ & [dzo] & jo & zyo \\
\hline$ち$ & {$[\mathrm{t} f \mathrm{i}]$} & chi & $\mathrm{ti}$ \\
\hline ちゃ & [t]a] & cha & tya \\
\hline ちゅ & {$\left[\mathrm{t} \int \mathrm{m}\right]$} & chu & tyu \\
\hline ちょ & [t]o] & cho & tyo \\
\hline$つ$ & [tsw] & tsu & tu \\
\hline づ and ず & [dzw] & $\mathrm{zu}$ & $\mathrm{zu}$ \\
\hline 了 & {$[\phi w]$} & $\mathrm{fu}$ & hu \\
\hline
\end{tabular}

Except for the volumes on Ryukyuan, Ainu, and Japanese dialects, whose phonetics differ from Standard Japanese, HJLL adopts the Kunreishiki system for rendering cited Japanese words and sentences but uses the Hepburn system for rendering conventional forms such as proper nouns and technical linguistic terms in the text and in the translations of examples.

Japanese sentences cited in HJLL look as below, where the first line transliterates a Japanese sentence in Kunreishiki Romanization, the second line contains interlinear glosses largely following the Leipzig abbreviation convention, and the third line is a free translation of the example sentence.

(1) Taroo wa Ziroo to Tookyoo e it-te kutusita o kat-ta. Taro TOP Jiro COM Tokyo ALL go-GER sock ACC buy-PST 'Taro went to Tokyo with Jiro and bought socks.'

The orthographic convention for rendering Japanese is to represent a sentence with an uninterrupted sequence of Sino-Japanese characters and katakana or hiragana syllabaries without a space for word segmentation, as in 太郎は次郎と東京へ行っ て靴下を買った for (1). In line with the general rules of Romanization adopted in 
books and articles dealing with Japanese, however, HJLL transliterates example sentences by separating word units by spaces. The example in (1) thus has 10 words. Moreover, as in it-te (go-GERUND) and kat-ta (buy-PAST) in (1), word-internal morphemes are separated by a hyphen whenever necessary, although this practice is not adopted consistently in all of the HJLL volumes. Special attention should be paid to particles like wa (topic), to 'with' and $e$ 'to, toward', which, in the HJLL representation, are separated from the preceding noun or noun phrase by a space (see 7.3). Remember that case and other kinds of particles, though spaced, form phrasal units with their preceding nouns.

\subsection{Word order}

As seen in (1), Japanese is a verb-final, dependent-marking agglutinative language. It is basically an SOV language which marks nominal dependent arguments by particles ( $w a, t o, e$, and $o$ above) and whose predicative component consists of a verbal stem with a variety of suffixes, auxiliary verbs, and semi-independent predicate extenders pertaining to the speech act of predication (see section 7.6). While a verb is rigidly fixed in sentence final position, the order of subject and object arguments may vary depending on pragmatic factors such as emphasis, background information, and cohesion. Thus, sentence (2a) with the unmarked order below, in principle may vary in multiple ways as shown by some possibilities in (2b)-(2d).

(2) a. Taroo ga Hanako ni Ziroo o syookai-si-ta.

Taro NOM Hanako DAT Jiro ACC introducing-do-PST

'Taro introduced Jiro to Hanako.'

b. Taroo ga Ziroo o Hanako ni syookai-si-ta.

c. Hanako ni Taroo ga Ziroo o syookai-si-ta.

d. Ziroo o Taroo ga Hanako ni syookai-si-ta.

Adverbs, likewise, can be rather freely placed, though each type of adverbs has its own basic position.

(3) a. Saiwainimo Hanako ga gohan o tai-te kure-te i-ta. luckily Hanako NOM rice ACC cook-GER GIVE-GER BE-PST 'Luckily Hanako had done the favor of cooking the rice (for us).'

b. Hanako ga saiwainimo gohan o tai-te kure-te i-ta.

c. Hanako ga gohan o saiwainimo tai-te kure-te i-ta. 
Notice that while the verbal complex in the sentence above is not as tightly organized as a complex involving suffixes, a sentence adverb cannot be placed within the verbal complex, showing that the sequence of tai-te kure-te i-ta forms a tighter constituent which, however, permits insertion of the topic particle wa after each of the gerund-forms. (See section 7.4 below on the nature of gerund-forms in Japanese.)

As the normal position of sentence adverbs is sentence initial, manner and resultative adverbs have an iconically-motivated position, namely before and after the object noun phrase, respectively, as below, though again these adverbs may move around with varying degrees of naturalness:

Hanako ga isoide gohan o tai-te kure-ta.
Hanako NOM hurriedly rice ACC cook-GER GIVE-PST
'Hanako hurried did the favor of cooking the rice (for us).'

$\begin{array}{lllll}\text { Hanako ga gohan o yawarakaku tai-te } & \text { kure-ta. } \\ \text { Hanako NOM rice ACC softly } & \text { cook-GER } & \text { GIVE-PST } \\ \text { 'Hanako did the favor of cooking the rice soft (for us).' } & \end{array}$

The fact that an object noun phrase can be easily separated from the verb, as in (2b.d), and that adverbs can freely intervene between an object and a verb, as in (5), has raised the question whether Japanese has a verb phrase consisting of a verb and an object noun phrase as a tightly integrated constituent parallel to the VP in English (cf. ${ }^{*}$ cook hurriedly the rice - the asterisk marks ungrammatical forms).

\subsection{NP structure}

Noun phrases, when they occur as arguments or adjuncts, are marked by case particles or postpositions that are placed after their host nouns. Because case markers can be set off by a pause, a filler, or even longer parenthetic material, it is clear that they are unlike declensional affixes in inflectional languages like German or Russian. Their exact status, however, is controversial; some researchers regard them as clitics and others as (non-independent) words.

Elaboration of Japanese noun phrases is done by prenominal modifiers such as demonstratives, genitive noun phrases, or adjectives, as below, indicating that Japanese is a consistent head-final language at both nominal and clausal levels.

(6) a. kono Taroo no kaban

this Taro GEN bag

lit. 'this Taro's bag' 


\section{b. Taroo no kono kaban \\ Taro GEN this bag \\ lit. 'Taro's this bag'}

Japanese lacks determiners of the English type that "close off" NP expansion. The literal translations of the Japanese forms above are ungrammatical indicating that English determiners like demonstratives and genitive noun phrases do not allow further expansion of an NP structure. Also seen above is the possibility that prenominal modifiers can be reordered just like dependents at the sentence level. The order of prenominal modifiers, however, is regulated by the iconic principle of placing closer to the head noun those modifiers that have a greater contribution in specifying the nature and type of the referent. Thus, descriptive adjectives tend to be placed closer to a head noun than demonstratives and genitive modifiers of non-descriptive types. Interesting is the pattern of genitive modifiers, some of which are more descriptive and are placed closer to the head noun than others. Genitives of the same semantic type, on the other hand, can be freely reordered. Compare:

(7) a. Yamada-sensei no kuroi kaban
Yamada-professor GEN black bag

'Professor Yamada's black bag'

b. $\quad{ }^{*}$ kuroi Yamada-sensei no kaban

(O.K. with the reading of 'a bag of Professor Yamada who is black')

(8) a. Yamada-sensei no gengogaku no koogi

Yamada-professor GEN linguistics GEN lecture

'Professor Yamada's linguistics lecture'

b. * gengogaku no Yamada-sensei no koogi

(O.K. with the reading of 'a lecture by Professor Yamada of linguistics')

(9) a. Yamada-sensei no kinoo no koogi

Yamada-professor GEN yesterday GEN lecture

lit. 'Professor Yamada's yesterday's lecture' 'Yesterday's lecture by

Professor Yamada'

b. Kinoo no Yamada-sensei no koogi

(10) a. oomori no sio-azi no raamen

big.serving GEN salt-tasting GEN ramen

lit. 'big-serving salt-tasting ramen noodles'

b. sio-azi no oomori no raamen 
(11) a. atui sio-azi no raamen

hot salt-tasting GEN ramen

'hot salt-tasting ramen noodles'

b. sio-azi no atui ramen

Numeral classifiers (CLFs) pattern together with descriptive modifiers so that they tend to occur closer to a head noun than a possessive genitive phrase.

(12) a. Taroo no san-bon no enpitu

Taro GEN three-CLF GEN pencil

'Taro's three pencils'

b. *san-bon no Taroo no enpitu

Numeral classifiers also head an NP, where they play a referential function and where they can be modified by a genitive phrase or an appositive modifier, as in (13a, b). They may also "float" away from the head noun and become adverbial, as in (13c).

(13) a. Taroo wa gakusei no san-nin o mikake-ta.

Taro TOP student GEN three-CLF ACC see.by.chance-PST

'Taro saw three of the students by chance.'

b. Taroo wa gakusei san-nin o mikake-ta.

Taro TOP student three-CLF ACC see.by.chance-PST

lit. 'Taro saw student-threes by chance.'

c. Taroo wa gakusei o san-nin mikake-ta.

Taro TOP student ACC three-CLF see.by.chance-PST

'Taro saw students, three (of them), by chance.'

As in many other SOV languages, so-called relative clauses are also prenominal and are directly placed before their head nouns without the mediation of "relative pronouns" like English which or who or "complementizers" like that. Predicates in relative clauses are finite, taking a variety of tense and aspect. The subject may be replaced by a genitive modifier. Observe (14a).

(14) a. Boku mo [Taroo ga/no kat-ta] hon o kat-ta. I ADVPART Taro NOM/GEN buy-PST book ACC buy-PST 'I also bought the book which Taro bought.'

b. Boku mo [Taroo ga/no kat-ta] no o kat-ta. I ADVPART Taro NOM/GEN buy-PST NM ACC buy-PST 'I also bought the one which Taro bought.' 
The structure used as a modifier in the relative clause construction can also head a noun phrase, where it has a referential function denoting an entity concept evoked by the structure. In Standard Japanese such a structure is marked by the nominalization particle no, as in (14b).

\subsection{Subject and Topic}

Some of the sentences above have noun phrases marked by the nominative case particle ga and some by the topic marker wa for what appear to correspond to subject noun phrases in the English translations. This possibility of ga- and wa-marking is seen below.

(15) a. Yuki ga siro-i.

snow NOM white-PRS

'The snow is white.'

b. Yuki wa siro-i.

snow TOP white-PRS

'Snow is white.'

As the difference in the English translations indicates, these two sentences are different in meaning. Describing the differences between topic and non-topic sentences has been a major challenge for Japanese grammarians and teachers of Japanese alike. The difference in the English translations above, however, is indicative of how these two sentences might differ in meaning. Sentence (15a) describes a state of affairs involving specific snow just witnessed, whereas (15b) is a generic statement about a property of snow unbounded by time. Thus, while (15a) would be uttered only when the witnessed snow is indeed white, (15b) would be construed true even though we know that there are snow piles that are quite dirty.

A similar difference is seen in verbal sentences as well.

(16) a. Tori ga tob-u.

bird NOM fly-NONPST

'A bird is flying/is

about to fly.'

b. Tori wa tob-u.

bird TOP fly-NONPST

'Birds fly.'

Non-topic sentences like (15a) and (16a) are often uttered with an exclamation accompanying a sudden discovery of a state of affairs unfolding right in front of one's eyes. 
The nonpast tense forms ( $-i$ for adjectives and $-(r) u$ for verbs) here anchor the time of this discovery to the speech time. The nonpast tense forms in (15a) and (16b), on the other hand, mark a generic tense associated with a universal statement.

These explanations can perhaps be extended to time-bound topic sentences seen in (17b) below.
a. Taroo ga hasit-ta.
Taro NOM run-PST
'Taro NOM ran.'
b. Taroo wa hasit-ta.
Taro TOP run-PST
'Taro ran.'

That is, while (17a) describes an occurrence of a particular event at a time prior to the speech time, (17b) describes the nature of the topic referent - that Taro was engaged in the running activity - as a universal truth of the referent, but universal only with respect to a specifically bound time marked by the past tense suffix.

Topics need not be subjects, and indeed any major sentence constituent, including adverbs, may be marked as topic in Japanese, as shown below.
a. Sono hon wa Taroo ga yon-de i-ru.
that book TOP Taro NOM read-GER be-NONPST
'As for that book, Taro is reading (it).'
b. Kyoo wa tenki ga yo-i.
today TOP weather NOM be. good-NONPST
'As for today, the weather is good.'
c. Sonnani wa hayaku wa hasir-e na-i.
that.way TOP quickly TOP run-POTEN NEG-NONPST
'That quickly, (I) cannot run.'

\subsection{Complex sentences}

Like other Altaic languages, compound sentences in Japanese do not involve a coordinate conjunction like English and. Instead, clauses are connected by the use of inflected verb forms, as in (19a) below, where the -i ending is glossed in the HJLL series as either INF (infinitive) or ADVL (adverbal) following the Japanese term ren'yō-kei for the form. While the $-i$ ending in the formation of compound sentences is still used today, especially in writing, the more commonly used contemporary form involves a conjunctive particle -te following the $-i$ infinitive form, as in (19b) below. In HJLL, this 
combination is glossed as GER (gerund), though the relevant Japanese forms do not have the major nominal use of English gerund-forms.

(19) a. Hana wa sak-i, tori wa uta-u. flower TOP bloom-INF bird TOP sing-NONPST 'Flowers bloom and birds sing.'

b. Hana wa sa-i.te, tori wa uta-u. flower TOP bloom-GER bird TOP sing-NONPST 'Flowers bloom and birds sing.'

Both the $-i$ and -ite forms play important roles in Japanese grammar. They are also used in clause-chaining constructions for serial events (20a), and in complex sentences (20b)-(20d), as well as in numerous compound verbs (and also in many compound nouns) such as sak-i hokoru (bloom-INF boast) 'be in full bloom', sak-i tuzukeru (bloom-INF continue) 'continue blooming', sa.i-te iru (bloom-GER be) 'is blooming', and sa.i-te kureru (bloom-GER GIVE) 'do the favor of blooming (for me/us)'.

(20) a. Taroo wa [ok-i/ok.i-te], [kao o ara-i/arat-te], Taro TOP rise-INF/rise-GER face ACC wash-INF/wash-GER [gohan o tabe-ta]. meal ACC eat.PST

'Taro got up, washed his face, and ate a meal.'

b. Taroo wa [sakana o tur-i] ni it-ta.

Taro TOP fish ACC catch-INF DAT go-PST

'Taro went to catch fish.'

c. Taroo wa [aruk-i nagara] hon o yon-da.

Taro TOP walk-INF SIMUL book ACC read-PST

'Taro read a book while walking.'

d. Taroo wa [Hanako ga ki-ta no] ni awa-na-katta.

Taro TOP Hanako NOM come-PST NM DAT see-NEG-PST.

'Taro did not see (her), even though Hanako came.'

(20d) has the nominalized clause marked by the particle no followed by the dative $n i$, also seen in (20b) marking the purposive form. In modern Japanese the no-ni sequence has been reanalyzed as a concessive conjunction. 


\subsection{Context dependency}

The context dependency of sentence structure in Japanese is much more clearly pronounced than in languages like English. Indeed, it is rare that Japanese sentences express all the arguments of a verb such as a subject (or topic) and an object noun phrase included in the sentences used above for illustrative purposes. A typical dialog would take the following form, where what is inferable from the speech context is not expressed.

$\begin{array}{rllll}\text { a. Speaker A: } & \text { Tokorode, Murakami Haruki no saisin-saku } \\ & \text { by.the.way Murakami Haruki GEN newest-work } \\ & \text { yon-da } \quad k a . & & & \\ & \text { read-PST } \mathrm{Q}\end{array}$

'By the way, have (you) read Haruki Murakami’s latest work?'
b. Speaker B: Un, moo yon-da.
uh-hu already read-PST
'Uh-hu, (I) have already read (it)'.

In (21a) A's utterance is missing a subject noun phrase referring to the addressee, and B's response in (21b) is missing both subject and object noun phrases. In some frameworks, sentences like these are analyzed as containing zero pronouns or as involving a process of "pro drop," which deletes assumed underlying pronouns. This kind of analysis, however, ignores the role of speech context completely and incorporates information contextually available into sentence structure. In an analysis that takes seriously the dialogic relationship between speech context and sentence structure, the expressions in (21) would be considered full sentences as they are.

\subsection{Predicative verbal complexes and extenders}

Coding or repeating contextually determinable verb phrases, as in (21b), is less offensive than expressing contextually inferable noun phrases, presumably because verb phrases have the predication function of assertion, and because they also code a wide range of other types of speech acts and of contextual information pertaining to the predication act. Declarative sentences with plain verbal endings like the one in (21b) are usable as "neutral” expressions in newspaper articles and literary works, where no specific reader is intended. In daily discourse, the plain verbal forms "explicitly" code the speaker's attitude toward the hearer; namely, that the speaker is treating the hearer as his equal or inferior in social standing, determined primarily by age, power, and familiarity. If the addressee were socially superior or if the occasion demanded formality, a polite, addressee honorific form with the suffix -masu would be used, as below. 
(22) Hai, moo yom-i-masi-ta.

yes already read-INF-POL-PST

'Yes, (I have) already read (it).'

Referent honorific forms are used when the speaker wishes to show deference toward the referent of arguments - subject honorific and object honorific (or humbling) forms, depending on the type of argument targeted. If (21b) were to be uttered in reference to a social superior, the following would be more appropriate:

Un, $\quad$ (Yamada-sensei $\quad$ wa) moo $\quad$ yom-are-ta.
uh-hu (Yamada-professor
'UOP)

This can be combined with the polite ending -masu, as below, where the speaker's deference is shown to both the referent of the subject noun phrase and the addressee:
Hai, (Yamada-sensei
wa) moo yom-are-masi-ta.
Yes (Yamada-professor TOP) already read-HON-POL-PST
'Yes, (Professor Yamada has) already read (it).'

As these examples show, Japanese typically employs agglutinative suffixes in the elaboration of verbal meanings associated with a predication act. The equivalents of English auxiliary verbs are either suffixes or formatives connected to verb stems and suffixed forms in varying degrees of tightness. These are hierarchically structured in a manner that expresses progressively more subjective and interpersonal meaning as one moves away from the verb-stem core toward the periphery. For example, in the following sentence a hyphen marks suffixal elements tightly bonded to the preceding form, an equal sign marks a more loosely connected formative, which permits insertion of certain elements such as the topic particle $w a$, and a space sets off those elements that are independent words following a finite predicate form, which may terminate the utterance.
(Taroo wa) ik-ase-rare-taku=na-katta
rasi-i
mitai
(Taro TOP) go-CAUS-PASS-DESI=NEG-PST CONJEC-NONPST UNCERT des-u wa.
COP.POL-NONPST SFP
'(Taro) appears to seem to not want to have been forced to go, I tell you.'

The final particle wa above encodes the information that the speaker is female. A male speaker would use yo or $d a$ yo, the latter a combination of the plain copula and yo, instead of desu wa above, or combinations such as da ze and da zo in rough speech. 
Non-declarative Japanese sentences, on the other hand, frequently suppress auxiliary verbs, the copula, and the question particle, especially in casual speech, where intonation and tone of voice provide clues in guessing the intended speech act. Casual interrogatives take the form of (26a) with a nominalization marker bearing a rising intonation, marked by the question mark in the transcription, whereas fuller versions have the interrogative particle $k a$ or a combination of the polite copula and $k a$, as in (26b).
a. Moo kaer-u no?
already return-NONPST NM
'Going home already?'
b. Moo kaer-u no (des.u) ka.
already return-NONPST NM (COP.POL-NONPST) Q
'Going home already?'

Requests are made with the aid of an auxiliary-like "supporting” verb kureru 'GIVE (ME THE FAVOR OF ...)', its polite form kudasai, or its intimate version tyoodai, as seen in (27a). Again, these forms are often suppressed in a highly intimate conversation and may result in a form like (27b).
a. Hayaku kaet-te kure/kudasai/tyoodai.
soon return-GER GIVE.IMP/GIVE.POL-IMP/GIVE.INTI
'(Please) come home soon (for me/us).'
b. Hayaku kaet-te ne.
soon return-GER SFP
'(Please) come home soon, won’t you?'

The use of dependent forms (e.g., the gerund -te form above) as independent sentences is similar to that of subjunctive forms in European languages as independent sentences, as illustrated by the English sentence below.

$$
\text { If you would give me five thirty-cent stamps. }
$$

Conditionals are used as independent suggestion sentences in Japanese as well. For example, (29a) has a fuller version like (29b) with the copula as a main-clause verb, which can also be suppressed, giving rise to the truncated form (29c).

(29) a. Hayaku kaet-tara?

quickly return-COND

lit. 'If return quickly.' 'Why don't you go home quickly?' 


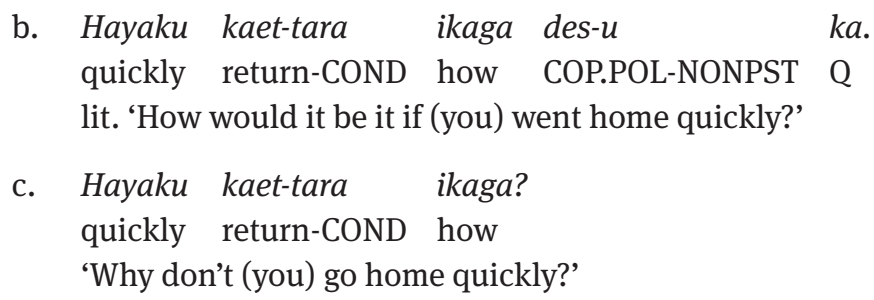

Understanding Japanese utterances requires full recourse to the elements of speech context, such as the nature of the speaker and the hearer and the social relationship between them, the information "in the air" that is readily accessible to the interlocutors, and the formality of the occasion. Indeed, the difficult part of the art of speaking Japanese is knowing how much to leave out from the utterance and how to infer what is left unsaid.

\section{Conclusion}

Many of the interesting topics in Japanese grammar introduced above are discussed in great detail in the Lexicon-Word Formation volume, the Syntax volume, and the present Semantics and Pragmatics volume of the HJLL series.. The Historical Linguistics volume also traces developments of some of the forms and constructions introduced above. The Sociolinguistics volume gives fuller accounts of sentence variations motivated by context and discourse genre.

\section{References}

Chamberlain, Basil H. 1895. Essay in aid of a grammar and dictionary of the Luchuan language. Transactions of the Asiatic Society of Japanese, vol. 23 supplement.

Frellesvig, Bjarke.2010. A history of the Japanese language. Cambridge: Cambridge University Press. Martin, Samuel E. 1975. A reference grammar of Japanese. New Haven: Yale University Press. Miller, Roy A. 1971. Japanese and the other Altaic languages. Chicago: University of Chicago Press. Shibatani, Masayoshi. 1990. The languages of Japan. Cambridge: Cambridge University Press. 


\section{Appendix: List of abbreviations for HJLL}

\begin{tabular}{|c|c|}
\hline 1 & first person \\
\hline 2 & second person \\
\hline 3 & third person \\
\hline A & agent-like argument of canonical transitive verb \\
\hline $\mathrm{ABL}$ & ablative \\
\hline ACC & accusative \\
\hline ACOP & adjectival copula \\
\hline ADJ & adjective \\
\hline AND & adnominal \\
\hline ADV & adverb(ial(izer)) \\
\hline ADVL & adverbial \\
\hline ADVPART & adverbial particle \\
\hline AGR & agreement \\
\hline AGT & agent \\
\hline ALL & allative \\
\hline $\mathrm{AN}$ & adjectival noun \\
\hline ANTIP & antipassive \\
\hline $\mathrm{AP}$ & adverbial particle, adjective phrase \\
\hline APPL & applicative \\
\hline ART & article \\
\hline ASP & aspect \\
\hline ATTR & attributive \\
\hline AUX & auxiliary \\
\hline AUXV & auxiliary verb \\
\hline $\mathrm{C}$ & consonant \\
\hline CAUS & causative \\
\hline CLF & classifier \\
\hline COHORT & cohortative \\
\hline COM & comitative \\
\hline COMP & complementizer \\
\hline COMPL & completive \\
\hline CONC & concessive \\
\hline CONCL & conclusive \\
\hline COND & conditional \\
\hline CONJEC & conjectural \\
\hline CONJCT & conjunctive \\
\hline CONT & continuative \\
\hline $\mathrm{COP}$ & copula \\
\hline CVB & converb \\
\hline DAT & dative \\
\hline
\end{tabular}




\begin{tabular}{ll} 
D & demonstrative \\
DECL & declarative \\
DEF & definite \\
DEM & demonstrative \\
DET & determiner \\
DESI & desiderative \\
DIST & distal \\
DISTR & distributive \\
DO & direct object \\
DU & dual \\
DUR & durative \\
EMPH & emphatic \\
ERG & ergative \\
ETOP & emphatic topic \\
EVID & evidential \\
EXCL & exclamatory, exclusive \\
EXPL & expletive \\
FOC & focus \\
FUT & future \\
GEN & genitive \\
GER & gerund(ive) \\
H & high (tone or pitch) \\
HON & honorific \\
HUM & humble \\
IMP & imperative \\
INCL & inclusive \\
IND & indicative \\
INDEF & indefinite \\
INF & infinitive \\
INS & instrumental \\
INT & intentional \\
INTERJEC & interjection \\
INTI & intimate \\
INTR & intransitive \\
IO & indirect object \\
IRR & irrealis \\
ITERA & iterative \\
k-irr & k-irregular (ka-hen) \\
L & low (tone or pitch) \\
LB & lower bigrade (shimo nidan) \\
LM & lower monograde (shimo ichidan) \\
LOC & locative \\
\hline &
\end{tabular}




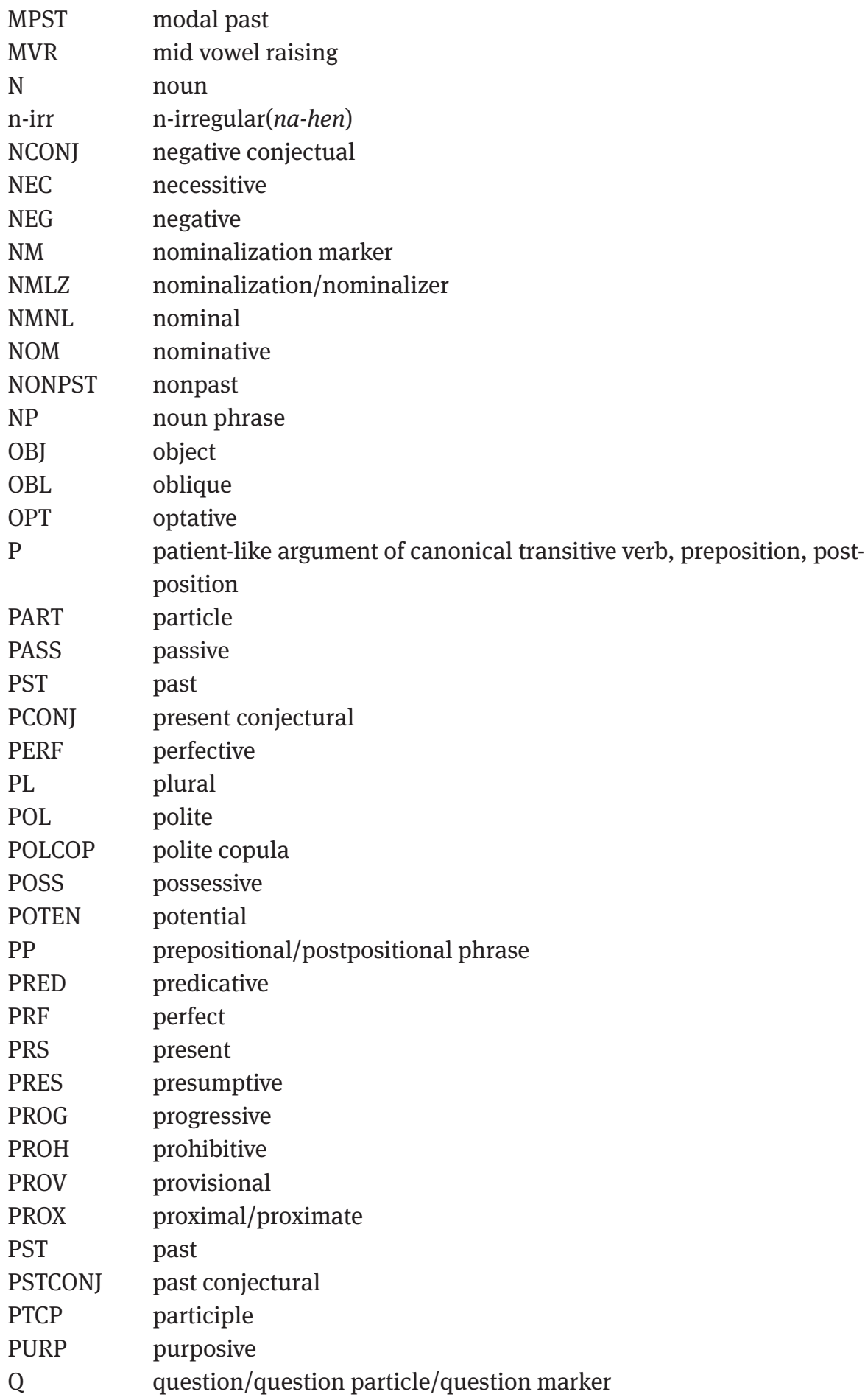




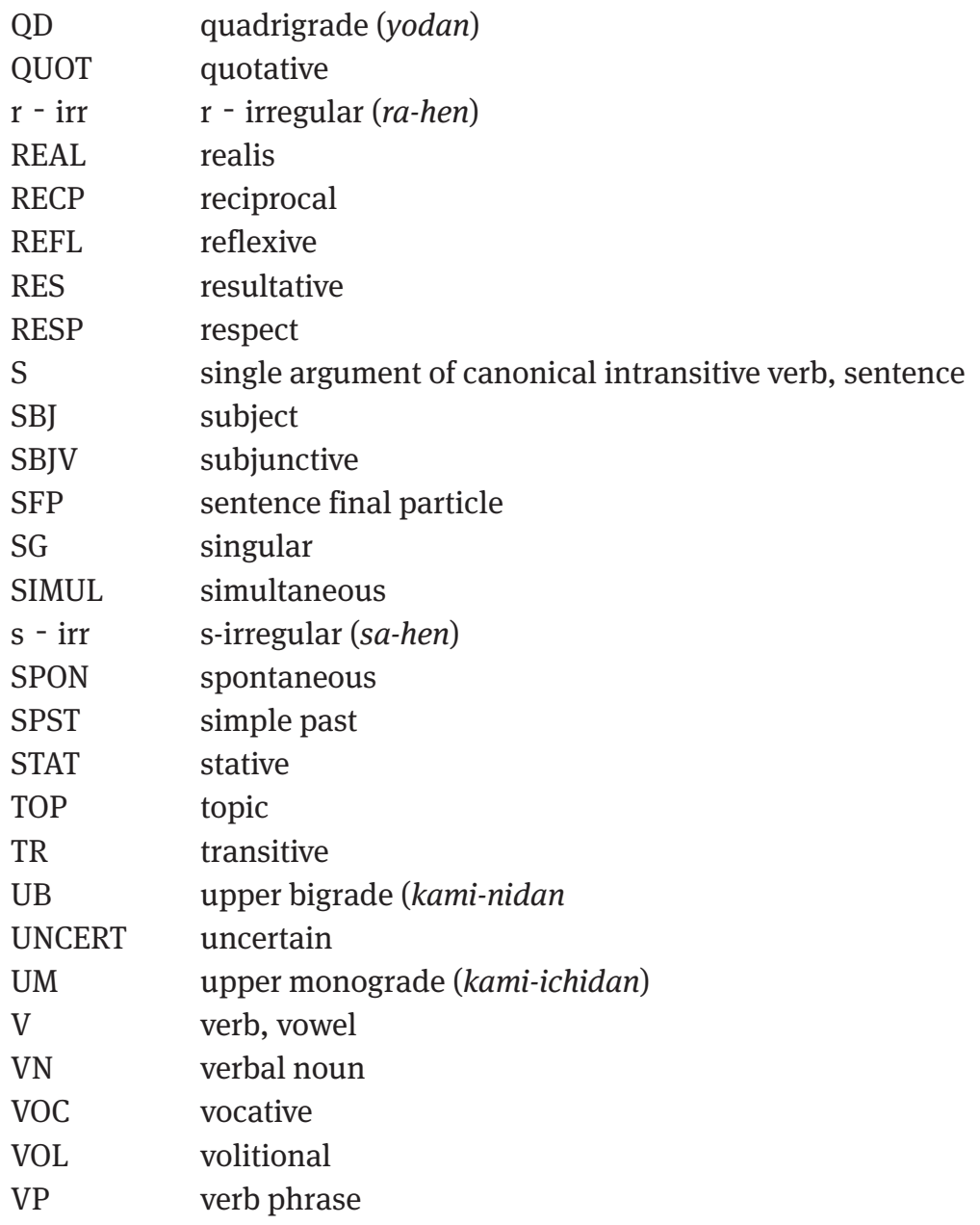

\section{Languages}

$\begin{array}{ll}\text { ConJ } & \text { contemporary Japanese } \\ \text { EMC } & \text { Early Middle Chinese } \\ \text { EMJ } & \text { Early Middle Japanese } \\ \text { EOJ } & \text { Eastern Old Japanese } \\ \text { J-Ch } & \text { Japano-Chinese } \\ \text { LMC } & \text { Late Middle Chinese } \\ \text { LMJ } & \text { Late Middle Japanese } \\ \text { JPN } & \text { Japanese } \\ \text { MC } & \text { Middle Chinese }\end{array}$


MJ Middle Japanese

MK Middle Korean

ModJ Modern Japanese

OC Old Chinese

OJ Old Japanese

pJ proto-Japanese

pK proto-Korean

SJ Sino-Japanese

Skt Sanskrit 